\title{
BMI-1 interacts with SMEK1 and inactivates sMEK1-induced apoptotic cell death
}

\author{
BOH-RAM KIM ${ }^{1,2}$, YOUNGJOO KWON ${ }^{2}$ and SEUNG BAE RHO ${ }^{1}$ \\ ${ }^{1}$ Research Institute, National Cancer Center, Ilsandong-gu, Goyang-si, Gyeonggi-do 410-769; \\ ${ }^{2}$ College of Pharmacy, Graduate School of Pharmaceutical Sciences, Ewha Global Top 5 Program, \\ Ewha Womans University, Seoul 120-750, Republic of Korea
}

Received June 20, 2016; Accepted November 14, 2016

DOI: $10.3892 /$ or.2016.5262

\begin{abstract}
The B lymphoma Mo-MLV insertion region 1 homolog (BMI-1) protein is activated in various types of tumors and associated with cancer development and tumor progression. However, the working role of BMI-1 in cellular signaling is not understood completely. In this study, we revealed one possible biologic mechanism of BMI-1 in cancer progression in vitro using a human ovarian tumor cell system. Suppressor of MEK1 (sMEK1), a pivotal regulator involved in the cellular biological response mechanism, was identified as a BMI-1-binding protein. Ectopic expression of BMI-1 activated cell growth by reducing sMEK1-stimulated apoptotic cell death and suppressing p21, p27 and p53 expression, while enhancing cyclin D1, CDK4 and Bcl-2 expression. The effect of BMI-1 on cell cycle and apoptotic regulatory proteins was also confirmed via silencing of BMI-1 expression. Subsequently, the promoter activities of p21 and p53 were inactivated significantly. However, BMI-1 overexpression noticeably increased $\mathrm{Bcl}-2$ and $\mathrm{NF}-\kappa \mathrm{B}$ activities. In addition, BMI-1 activated the PI3K/mTOR/4E-BP1 signaling pathways, and sMEK1 significantly inhibited BMI-1-stimulated onco-
\end{abstract}

Correspondence to: Dr Seung Bae Rho, Research Institute, National Cancer Center, 323 Ilsan-ro, Ilsandong-gu, Goyang-si, Gyeonggi-do 410-769, Republic of Korea

E-mail: sbrho@ncc.re.kr

Professor Youngjoo Kwon, College of Pharmacy, Graduate School of Pharmaceutical Sciences, Ewha Global Top 5 Program, Ewha Womans University, Seoul 120-750, Republic of Korea

E-mail: ykwon@ewha.ac.kr

Abbreviations: BMI-1, B lymphoma Mo-MLV insertion region 1 homolog; PcG, polycomb group protein; sMEK1, suppressor of mek1; PP4R3, protein phosphatase 4 regulatory subunit 3; CDK, cyclin-dependent kinases; HDAC3, histone deacetylase 3; CRTC, CREB regulated transcriptional coactivator; ONPG, $O$-nitrophenyl $\beta$-D-galactopyranoside; PDK1, 3-phosphoinositide-dependent protein kinase-1; mTOR, mammalian target of rapamycin

Key words: BMI-1, sMEK1, protein-protein interaction, pro-apoptotic activity, ovarian tumor metastasis genesis. These insights provide evidence that BMI-1 activates cell growth and suppresses apoptosis. Collectively, our data indicate that BMI-1 plays a pivotal role in the progression of ovarian cancer, thus representing a novel target for antitumor therapy of ovarian cancer.

\section{Introduction}

The B lymphoma Mo-MLV insertion region 1 homolog (BMI-1) protein is associated with cancer development and tumor progression; its roles include tumor invasion, metastasis and repression of apoptotic cell death or cell senescence (1-4). The BMI-1 gene is an important member of the polycomb group protein $(\mathrm{PcG})$ family, which plays oncogenic roles in several types of tumors. Structurally, BMI-1 has a conserved RING finger domain at the N-terminus and a central helix-turn-helix motif (5). Upregulation of BMI-1 was found in various human cancers including ovarian, breast, cervical (6-8), glioblastoma multiforme (9), and colorectal cancers $(10,11)$, as well as high-grade B-cell non-Hodgkin lymphomas (NHLs) (12), skin cancer (13), neuroblastomas (14), and pancreatic cancer (15). BMI-1 overexpression has been associated with poor survival. Previous studies have discovered that BMI-1 interacts with a number of tumor-related signaling pathways, specifically, $\mathrm{NF}-\kappa \mathrm{B}$ activation and $\mathrm{p} 16 / \mathrm{Rb}$ and $\mathrm{p} 19^{\mathrm{Arf}} / \mathrm{MDM} 2 / \mathrm{p} 53$ tumor suppressive signaling pathway inhibition (16-18). It has also been reported that BMI-1 controls the expression of several genes, including the PTEN tumor suppressors, HOX and WWOX (19-21). Also, Cao et al (22) validated that compounds from one of our top series suppressed tumor growth and significantly decreased intratumoral levels of BMI-1. Recently, BMI-1 was considered as a promising drug target for lung adenocarcinomas with low CEBP $\alpha$ expression (23), pancreatic cancer with gemcitabine resistance (24), and MDR1 mediated chemoresistance (25). However, the precise roles of BMI-1 in tumor invasion and metastasis are largely unknown.

The suppressor of MEK1 (sMEK1) tumor suppressor protein, defined as protein phosphatase 4 regulatory subunit 3 (PP4R3), is a vital modulator involved in cellular biological and physiological functions, such as apoptotic cell death, microtubule organization, cell cycle arrest, DNA damage checkpoints, and PI3K/Akt/mTOR signaling pathways. It is a highly conserved member of the phosphatase family of serine/ 
threonine phosphatases associated with sensitivity to traditional chemotherapeutic drugs, such as cisplatin, gemcitabine and paclitaxel (26-30). sMEK1 functionally binds with several intracellular proteins that cooperate with biological and physiological processes, as well as apoptotic cell death, microtubule growth and cell cycle arrest, including target of rapamycin (TOR) (31), insulin receptor substrate 4 (IRS4) (32), adenosine triphosphate (ATP)-dependent chaperonin (33), and histone deacetylase 3 (HDAC3) $(28,34)$. Previous studies have validated that ectopic expression of sMEK upregulates hepatic gluconeogenesis, whereas knockdown of sMEK decreases blood glucose levels while enhancing hepatic CREB-regulated transcriptional coactivator (CRTC) phosphorylation. The sMEK null protein is an important regulator of hepatic gluconeogenesis (35). Byun et al (30) reported that sMEK1 additively promotes the proapoptotic activity of gemcitabine by activating p53 expression. In addition, the expression of sMEK1 is remarkably decreased in ovarian and cervical cancer patient tissues, as well as in cancer cell lines, and is hypermethylated (36). Recently, we reported that sMEK1 inhibits endothelial cell proliferation and angiogenesis by suppressing VEGFR-2-mediated PI3K/Akt/eNOS signaling pathway in ovarian tumors (37). More specifically, protein phosphorylation/dephosphorylation plays an important role in various cellular conditions involved in the molecular basis for diseases such as diabetes, stroke, hypertension, and unusual movements within the cardiovascular system.

In this study, a yeast two-hybrid assay system was utilized to screen a human cDNA library for novel BMI-1 interacting protein partners in order to start the characterization of BMI-1-dependent signaling pathways. Furthermore, we showed that BMI-1 and the sMEK1 complex regulate the cellular physiological function of the binding protein. We also demonstrated that the signaling pathways were affected by BMI-1, and that the pattern of expression for the apoptotic-regulatory proteins was mediated by BMI-1 expression under siRNA (specific to BMI-1) of the sMEK1stimulated apoptotic features observed in ovarian carcinoma cells. These observations suggest a role for BMI-1 in ovarian tumorigenesis and it may be a potential target for antitumor therapy of ovarian cancer.

\section{Materials and methods}

Cell lines, cell culture and antibodies. Human ovarian cancer cell lines (SKOV-3 and OVCAR-3) and human embryonic kidney 293T (HEK293T) cells were purchased from the American Type Culture Collection (ATCC, Manassas, VA, USA). Cells were grown according to the manufacturer's instructions. Wortmannin and LY294002 chemicals were obtained from Sigma (St.Louis, MO, USA). The primary antibodies used in this study were as follows: anti-BMI-1, anti-cyclin D1, anti-CDK4, anti-Mcl-1, anti-p53, anti-phospho-PI3K (Tyr508), anti-PI3K, anti-phospho-Akt (Ser473), anti-Akt (Santa Cruz Biotechnology, Santa Cruz, CA, USA), anti-sMEK1 (Abcam, Cambridge, UK), anti-p21, anti-p27, anti-NF-кB (Ab-1; Oncogene, Cambridge, MA, USA), anti-Bax, anti-Bcl-xL, anti-Bcl-2, antiphospho-PDK1, anti-PDK1, anti-phospho-mTOR, anti-mTOR, anti-phospho-4E-BP1, anti-4E-BP1 (Cell Signaling, Beverly, MA, USA), and $\beta$-actin (Sigma).
Western blot analysis. For whole protein extraction, cultured ovarian cancer cells were harvested, rinsed with PBS, centrifuged, and disrupted by adding cell lysis buffer containing protease inhibitor cocktail $(50 \mathrm{mM}$ Tris, $\mathrm{pH} 7.2,150 \mathrm{mM}$ $\mathrm{NaCl}, 1 \%$ Triton X-100, $1 \mu \mathrm{g} / \mathrm{ml}$ leupeptin, $1 \mu \mathrm{g} / \mathrm{ml}$ pepstatin, $2 \mu \mathrm{g} / \mathrm{ml}$ aprotinin, and $200 \mu \mathrm{g} / \mathrm{ml}$ phenylmethylsulfonyl fluoride) at $4{ }^{\circ} \mathrm{C}$ for $1 \mathrm{~h}$. Proteins were subsequently separated by $8-12 \%$ SDS-PAGE and transferred to Immobilon $\mathrm{P}$ membranes (Millipore Corp., Billerica, MA, USA). After blocking, the membranes were incubated with the indicated primary specific antibodies at $4^{\circ} \mathrm{C}$ overnight. The membranes were rinsed three times in TBST washing buffer and incubated with horseradish peroxidase-conjugated secondary antibodies. Protein bands were developed using the ECL detection system (GE Healthcare, Little Chalfont, Buckinghamshire, UK).

Co-immunoprecipitation analysis. For co-immunoprecipitation, cells were rinsed in phosphate-buffered saline (PBS) and dissolved in cell lysis buffer including $50 \mathrm{mM}$ Tris-HCl, $\mathrm{pH} 7.2,150 \mathrm{mM} \mathrm{NaCl}, 1 \%$ Triton X-100 and a protease inhibitor cocktail (Sigma). Lysates were then incubated with anti-Flag antibody (Santa Cruz) and precipitated using protein A-agarose (Invitrogen, Carlsbad, CA, USA). Precipitated proteins were separated by $10 \%$ sodium dodecyl sulfate polyacrylamide gel electrophoresis (SDS-PAGE), transferred to an Immobilon-P membrane (GE Healthcare, Piscataway, NJ, USA), and subjected to immunoblot analysis using either anti-BMI-1 or anti-sMEK1 antibodies. Enhanced chemiluminescent (ECL) western blotting detection reagent (Pierce, Rockford, IL, USA) was used to visualize the gels. $\beta$-actin served as an internal control.

Gene silencing by small interference RNA (siRNA). Oligonucleotides containing the BMI-1 siRNA sequence 5'-ATAT GAAGAGAAGAAGGGATT-3' were synthesized using an RNAi construction kit (Ambion, Austin, TX, USA) and transfected into cells using Lipofectamine 2000 reagent (Invitrogen) according to the manufacturer's instructions to silence endogenous BMI-1 expression. Cells were seeded for $24 \mathrm{~h}$ followed by transfection with $150 \mathrm{nM}$ siBMI-1. At $24 \mathrm{~h}$ after transfection, cells were prepared for MTT assays and immunoblot analysis.

Apoptotic cell death analysis. Cells were seeded on 6-well plates at a density of $1 \times 10^{5}$ per well and transfected. Next, cells were incubated with FITC-labeled Annexin V and propidium iodide (PI) for 15 min according to the manufacturer's instructions (BD Pharmingen, Mississauga, ON, Canada) and analyzed using a fluorescence activated cell sorting (FACS) Vantage BD FACSCalibur flow cytometer. To determine cell viability, the relative rate of cell viability was evaluated via MTT assay. Cells were grown at a density of $4.5 \times 10^{3}$ per well in 96-well plates. Three days after transfection, fresh medium including $10 \%$ fetal bovine serum (FBS) and $20 \mu 1$ of 3-(4,5-dimethylthiazol-2-yl)-2.5-diphenyl- ${ }^{2} \mathrm{H}$-tetrazolium bromide (MTT) solution (Sigma, $5 \mu \mathrm{g} / \mathrm{ml}$ ) was added to each well and incubated for an additional $4 \mathrm{~h}$ at $37^{\circ} \mathrm{C}$. After centrifugation at $500 \mathrm{~g}$ for $10 \mathrm{~min}$, the supernatant was removed from the wells, and the formazan product was dissolved in dimethyl sulfoxide (DMSO). The amount of MTT-formazan 
A

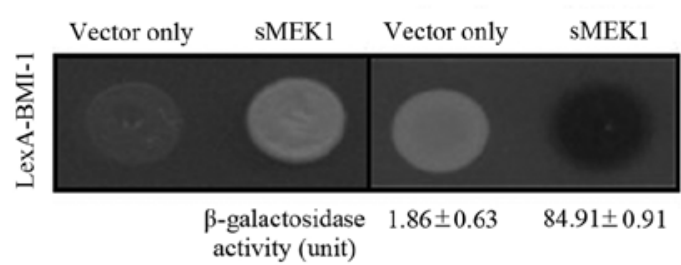

B

\begin{tabular}{|lll} 
Input $\quad 1 \quad 2 \quad 2$ & IP: Anti-Flag \\
\hline & WB: BMI-1 \\
& WB: sMEK1 \\
& WB: $\beta$-actin in WCL
\end{tabular}

C
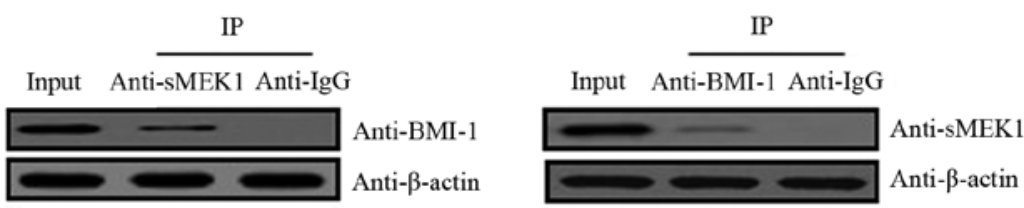

D

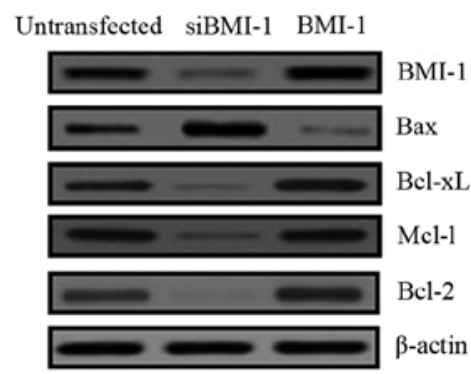

Figure 1. Functional interaction between BMI-1 and sMEK1 proteins. (A) Positive interactions were determined by observing cell growth over 3 days at $30^{\circ} \mathrm{C}$ on medium lacking leucine. The values of $\beta$-galactosidase activity (unit), measured by adding $O$-nitrophenyl $\beta$-D-galactopyranoside (ONPG), are indicated below the corresponding lanes. (B) Co-immunoprecipitation of BMI-1 with sMEK1. Immunoprecipitation was performed using an anti-Flag antibody and lysates from both transfected ovarian carcinoma cell lines. After immunoprecipitation, precipitated proteins were immunoblotted using anti-BMI-1 and anti-sMEK1 antibodies. Lane 1, pcDNA3.1 (vector only) and pcDNA3.1/Flag-sMEK1 transfectants; lane 2, pcDNA3.1-BMI-1 and pcDNA3.1/Flag-sMEK1 transfectants. (C) Co-immunoprecipitation of endogenous sMEK1 and BMI-1 indicated an interaction in HEK293T cells. $\beta$-actin was used as a loading control. (D) Protein expression levels of Bcl-2 family genes were assessed via western blot analysis of ovarian cancer cells transfected with BMI-1 or BMI-1 RNAi. $\beta$-actin was used as a protein loading control, and antibodies detecting BMI-1, Bax, Bcl-xL, Mcl-1 and Bcl-2 were used.

added was determined by the absorbance, calculated using a microplate reader at $540-550 \mathrm{~nm}$.

Luciferase reporter gene analysis. BMI-1 luciferase activity in vitro was carried out as reported previously (38). In brief, cells at $85 \%$ confluency were transfected using a BMI-1 reporter plasmid vector. After lysis using RIPA buffer, lysates were cleared by centrifugation at $14,000 \mathrm{rpm}$ for $15 \mathrm{~min}$, and cell extracts were incubated with a luciferase substrate reagent at room temperature for $30 \mathrm{~min}$ according to the manufacturer's instructions. Five-microliter aliquots of each sample were measured using a MicroLumat Plus LB96V luminometer (Berthold Technologies, Bad Wildbad, Germany).

Data and statistical analysis. All results are presented as the means \pm standard deviations (SD) from at least three independent experiments. Statistical comparisons between the different groups were analyzed using the Student's t-test. Significance was set at $\mathrm{P}<0.05$.

\section{Results}

Physical interaction between BMI-1 and sMEK1. To explore the cellular biological and physiological relevance of BMI-1 on the effects of tumor metastasis, we performed yeast two-hybrid and co-immunoprecipitation assays to identify potential BMI-1-interacting partners. The human cDNA library fused to the transcriptional activator $\mathrm{pJG} 4-5 / \mathrm{B} 42$ gene was introduced into yeast cells containing the pGilda/LexA-BMI-1 as bait. Approximately $6.0 \times 10^{6}$ independent transformants were pooled. Five positive colonies were obtained after respreading on selection media (Ura-, His-, Trp-, and Leu-). Of the five sequenced clones, all encoded sMEK1 (accession no. NM_001284280), indicating that BMI-1 interacted with sMEK1. To confirm these results, positive interaction was monitored by both cell growth on leucine-deficient plates and ONPG $\beta$-galactosidase activity. An empty plasmid (vector only) served as a negative control. As shown in Fig. 1A, $\beta$-galactosidase activity was fully activated, indicating an interaction between BMI-1 and sMEK1 $(84.91 \pm 0.91)$, but such was not observed with the empty plasmid (vector only, 1.86 \pm 0.63 ). To further confirm a direct interaction between BMI-1 and sMEK1 as revealed in the yeast two-hybrid assay, co-immunoprecipitation experiments were used. Gene constructs of sMEK1 (pcDNA3.1/ Flag-sMEK1) and BMI-1 (pcDNA3.1/BMI-1) or sMEK1 (pcDNA3.1/Flag-sMEK1) and vector only (pcDNA3.1), were co-transfected into ovarian carcinoma cells. Next, immunoprecipitation was performed using an anti-Flag antibody in lysates 
A
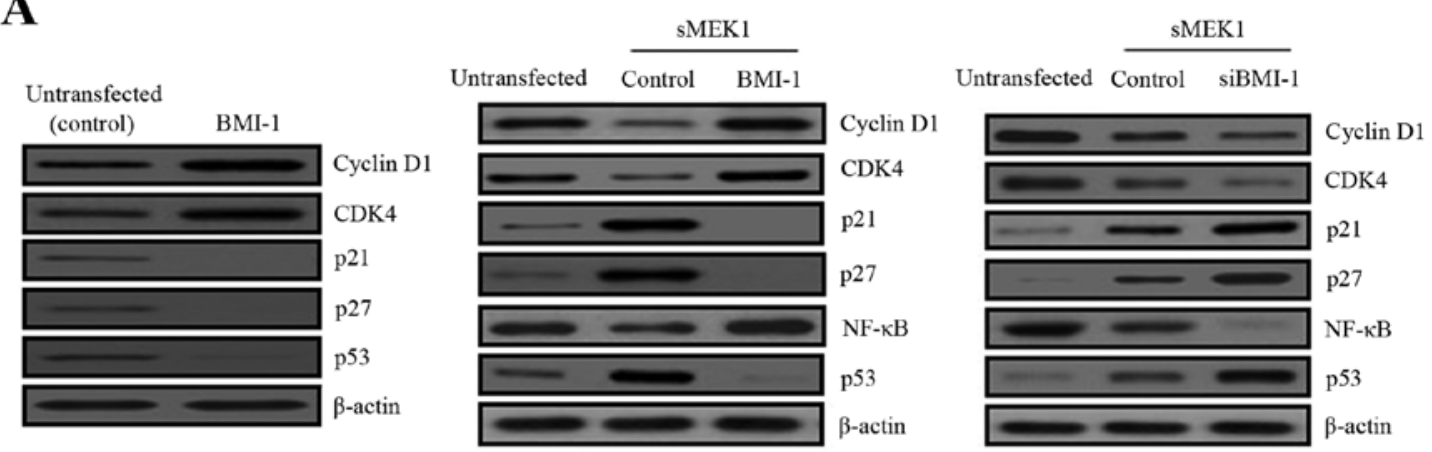

B
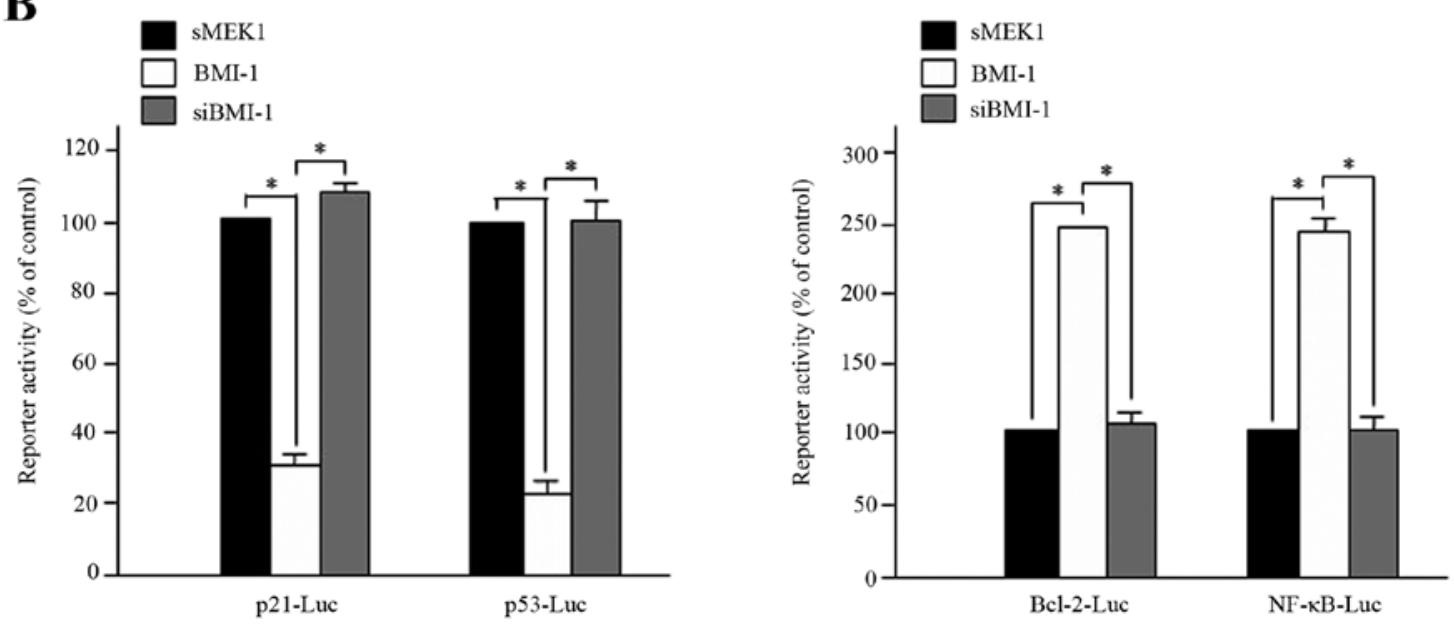

Figure 2. Effects of BMI-1 on sMEK1-induced apoptosis, p21 and NF-kB activity. (A) Cells were transfected with BMI-1 expression plasmid (pcDNA3.1/BMI-1) (left) and sMEK1 for $24 \mathrm{~h}$, and sMEK1-expressing cells were then transiently transfected with a control, BMI-1 (middle) or siBMI-1 (right), respectively. After $48 \mathrm{~h}$, cells were collected and treated with lysis buffer. Cell lysates were subsequently subjected to immunoblot analysis. Protein expression levels of cell cycleand apoptosis-related genes were evaluated. Protein expression was assessed via immunoblotting using specific antibodies. (B) Promoter activities of p21, p53, $\mathrm{Bcl}-2$ and NF- $\mathrm{KB}$ were measured using a luciferase reporter-gene assay system with a p21 promoter reporter (p21-Luc), p53 (p53-Luc), Bcl-2 (Bcl-2-Luc) and

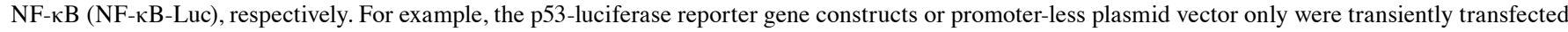
into sMEK1-induced ovarian carcinoma cells. Cells were incubated for $24 \mathrm{~h}$ and then added to lysis buffer. After collection by centrifugation, cells were lysed, mixed with luciferase reaction substrate, and assayed for luciferase activity. Experiments were performed in triplicate, and error bars represent the means \pm SD Differences between groups were considered significant at the level of ${ }^{*} \mathrm{P}<0.05$.

from both transfected cell lines. After immunoprecipitation, precipitated proteins were subjected to immunoblotting using anti-BMI-1 or anti-sMEK1 antibodies. As shown in Fig. 1B, pcDNA3.1-BMI-1 co-immunoprecipitated with pcDNA3.1/ Flag-sMEK1 (lane 2, upper panel), but not with pcDNA3.1 (vector only) (lane 1, upper panel). Subsequently, cellular interaction between these two proteins was also demonstrated by co-immunoprecipitation of endogenous BMI-1 and sMEK1. As shown in Fig. 1C, endogenous BMI-1 co-immunoprecipitated directly with sMEK1. We next evaluated BMI-1-induced cell growth by determining the expression of the apoptosis-related proteins Bax, Bcl-xL, Mcl-1 and Bcl-2. These proteins are wellknown pivotal regulators of apoptotic cell death and growth. As presented in Fig. 1D, Bax expression was decreased, while Bcl-xL, Mcl-1 and Bcl-2 were increased by BMI-1, compared with the non-transfectants. Consistent with these results, cells transfected with a specific BMI-1 RNAi (siBMI-1) showed enhanced Bax expression, whereas Bcl-xL, Mcl-1 and Bcl-2 were decreased remarkably by siBMI-1. Collectively, these results strongly indicate that BMI-1 directly interacts with sMEK1 under biologic conditions.
sMEK1 controls cell cycle- and apoptosis-associated proteins. Cell cycle control is a fundamental process in cellular homeostasis and involves DNA repair, DNA replication and cell division. This regulation is generally mediated by cyclin and cyclin-dependent kinases (CDKs). In particular, CDKs are serine/threonine kinases that play an important role in the complex feedback regulation of cell cycle progression. Therefore, we examined expression levels of cell cycle- and apoptotic cell death-associated proteins via western blot analysis. As shown in Fig. 2A, overexpression of BMI-1 increased the expression of cyclin D1 and CDK4 remarkably, but decreased the expression of p21 and p27, acting as a CDK inhibitor. These results demonstrate that overexpression of BMI-1 strikingly interrupts sMEK1-induced apoptosis (Fig. 2B). Nuclear factor kappa B (NF-kB) and Bcl-2 family genes, as well as the p53 tumor suppressor, are major modulators of cell growth and apoptosis. To explore the functional effects of BMI-1 on sMEK1-induced apoptotic cell death, cells were transfected with either a BMI-1 expression plasmid or siBMI-1, and promoter activity was then measured using a dual luciferase reporter gene assay. As presented in Fig. 2B, the 
A

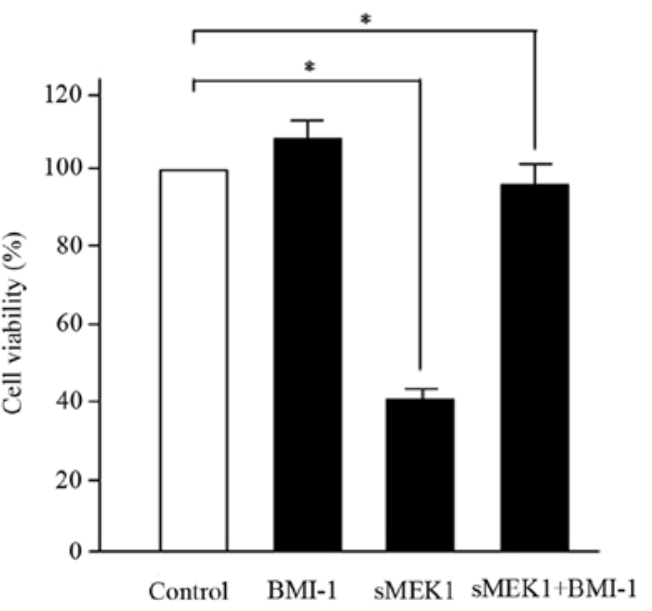

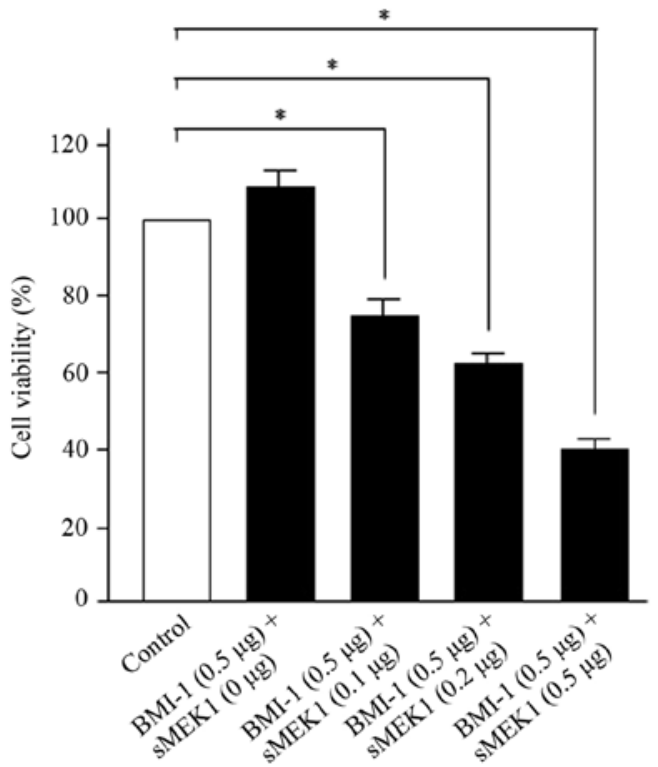

B

Control
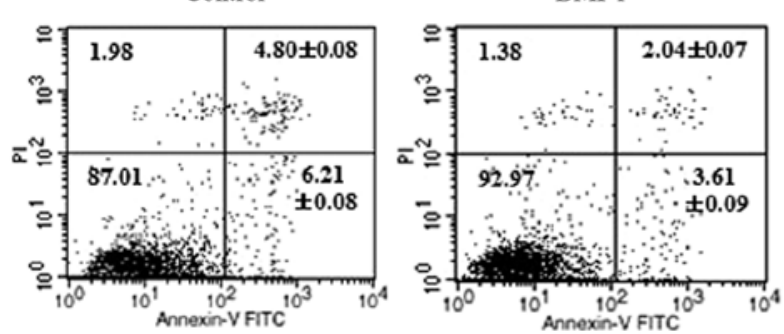

SMEK1

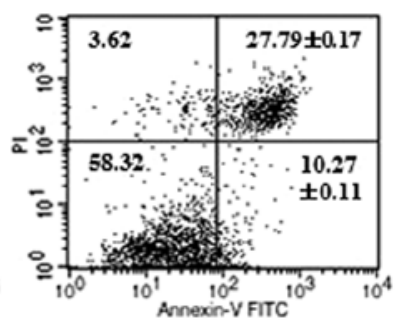

sMEK1+BMI-1

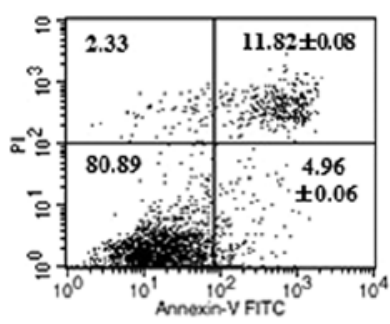

Figure 3. BMI-1 inhibits sMEK1-induced apoptosis in ovarian cancer cells. A cell viability assay (A) and FACS analysis (B) were performed using ovarian SKOV-3 and OVCAR-3 tumor cells transfected with the indicated cDNA constructs (data not shown). The control represents transfection of the expression plasmid vector only (without insert). (A) Relative rates of cell proliferation were measured using an MTT assay. Amounts of MTT-formazan were calculated by measuring the absorbance at $540 \mathrm{~nm}$, and absorbances of the samples were converted to relative proliferation rates. Results represent the means \pm SD of at least three independent experiments performed in triplicate. Differences between groups were considered significant at the level of * $\mathrm{P}<0.05$. (B) Early- and late-stage apoptosis induced by sMEK1 and sMEK1 plus siBMI-1 (data not shown) was analyzed using a fluorescein isothiocyanate (FITC)-labeled Annexin V assay.

promoter activities of $\mathrm{p} 21$ and p53 were significantly reduced, whereas Bcl-2 and NF- $\mathrm{BB}$ activity were noticeably enhanced by BMI-1 overexpression. Taken together, these results demonstrate clearly that BMI-1 controls apoptosis modulator protein levels through downregulation of p53 and upregulation of NF- $\kappa \mathrm{B}$ activity during sMEK1-induced apoptosis in tumor cells.

BMI-1 inhibits sMEK1-stimulated apoptosis in ovarian carcinoma cells. To explore the biological function of BMI-1 during sMEK1-induced apoptosis, ovarian carcinoma cells were transfected with BMI-1, sMEK1, or sMEK1 plus BMI-1. Control transfectant contained the expression vector only. According to the reduced number of cells, which is indicative of cell viability, sMEK1-transfected cells were suppressed to $\sim 60 \%$ compared with control cells. In contrast, enhanced viability of the BMI-1 and sMEK1 plus BMI-1 transfectants was observed (Fig. 3A, left panel). Furthermore, after cotransfection with BMI-1 $(0.5 \mu \mathrm{g})$ and sMEK1 $(0-0.5 \mu \mathrm{g})$, apoptotic cell death increased gradually in a dose-dependent manner (Fig. 3A, right panel). Subsequently, flow cytometric analysis confirmed that the loss of viability was in fact due to cell death. Cells were transfected with a control vector (expression plasmid vector only), BMI-1, sMEK1, or a combination of sMEK1 and BMI-1. As shown in Fig. 3B, cell growth of ovarian cancer cells was inhibited by sMEK1 transfection compared with that of control transfectants. Interestingly, cell viability was recovered in sMEK1-expressing BMI-1 transfectants (sMEK1 plus BMI-1) compared with sMEK1-expressing only transfectants, whereas sMEK1-expressing siBMI-1 transfectants (sMEK1 plus siBMI-1) exhibited suppression of cell viability by $20 \%$ compared with siBMI-1-expressing cells (siBMI-1 plasmid only; data not shown). These results strongly indicate that BMI-1 has an antagonistic effect on sMEK1-mediated apoptotic cell death.

sMEK1 causes a decrease in PI3K/mTOR/4E-BP1 phosphorylation. To explore the underlying molecular mechanism by which BMI-1 promotes PI3K activation, we examined the involvement of PDK1, Akt, mTOR, and 4E-BP1, all of which are downstream signaling cascade components of the PI3K pathway. Cell lysates from sMEK1-expressing cells (control) and BMI-1 transfected cells were examined by western blot analysis. BMI-1-induced phosphorylation of PI3K, Akt and mTOR plays a major role in BMI-1-stimulated tumorigenesis, migration, invasion, and tumor metastasis. As presented in 
A

Un- sMEK1 only sMEK $1+$ sMEK $1+$ sMEK $1+$ transfected (control) BMI-1 Wortmannin LY294002
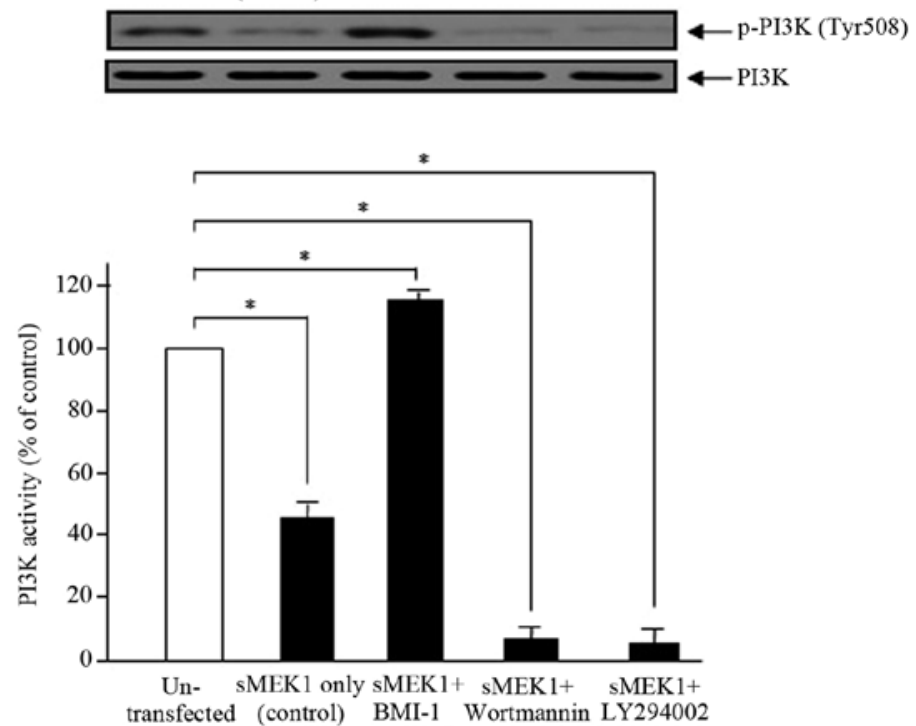

B

\begin{tabular}{|c|c|c|c|c|c|}
\hline \multirow[b]{2}{*}{ Untransfected } & \multicolumn{4}{|c|}{ sMEK1 } & \multirow[b]{2}{*}{ (BMI-1) } \\
\hline & $0 \mu \mathrm{g}$ & $0.2 \mu \mathrm{g}$ & $0.5 \mu \mathrm{g}$ & $1.0 \mu \mathrm{g}$ & \\
\hline$=$ & & & $=$ & - & $\longleftarrow$ p-Akt (Ser473) \\
\hline
\end{tabular}

C

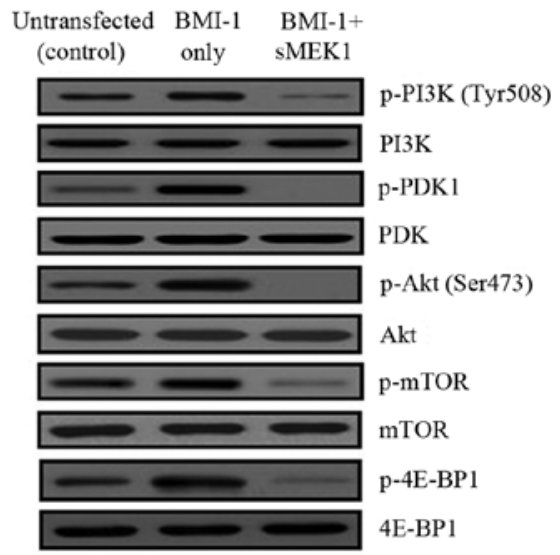

Figure 4. Effects of BMI-1 on PI3 kinase activity and phosphorylation of the Akt/mTOR signaling components by sMEK1 transfection. (A) The effects of BMI-1 on PI3K activity, in the presence of sMEK1, was measured using an in vitro PI3 kinase assay. Data represent the means \pm SD from three independent experiments with similar results. Differences between groups were considered significant at the level of * $\mathrm{P}<0.05$. Box, cells transfected with sMEK1 were transfected/treated with the BMI-1 expression plasmid, wortmannin, or LY294002 for 24 h, collected, and subjected to immunoblotting to identify the indicated proteins. PI3K was used to verify equal sample loading. (B) sMEK1-expressing cells were transfected with various concentrations of the BMI-1 expression plasmid. Akt phosphorylation was determined by western blot analysis. Non-phosphorylated Akt served as a loading control. (C) Cells were transfected with control, BMI-1, or BMI-1 plus sMEK1, harvested, and treated with lysis buffer. After collection by centrifugation, equal amounts of cellular protein $(30 \mu \mathrm{g})$ were separated by $10 \%$ SDS-PAGE, followed by immunoblotting using specific antibodies (PI3K/phosphorylated PI3K, PDK1/phosphorylated PDK1, Akt/phosphorylated Akt, mTOR/phosphorylated mTOR and 4E-BP1/phosphorylated-4E-BP1). All experiments were performed at least three times with consistent and similar results.

Fig. 4, sMEK1-induced PI3K and Akt dephosphorylation was significantly restored by BMI-1. Ectopic BMI-1 expression also enhanced Akt phosphorylation in a dose-dependent manner (Fig. 4B). These data were comparable to those of wortmannin and LY294002, well-known PI3K inhibitors. Wortmannin and LY294002 were shown to additively decrease (by 40-45\%) the PI3 kinase activity induced by sMEK1 (Fig. 4A). We next investigated the phosphorylation of essential components of the mTOR/4E-BP1 signaling pathways. As presented in Fig. 4C, sMEK1 significantly reduced PDK1 phosphorylation, as well as the phosphorylation of mTOR and 4E-BP1. Collectively, our results indicate that BMI-1 recovers SMEK1-stimulated apoptotic cell death through activation of the PI3K/mTOR/4E-BP1 signaling pathway in ovarian tumor cells.

\section{Discussion}

Previous studies have reported that overexpression of BMI-1 correlates with therapy failure in various cancer types, including ovarian, breast, lung, and prostate tumor patients (22,39-42). BMI-1 is significantly overexpressed in ovarian cancer and is correlated with a poor prognosis, indicating that this protein participates in the development and progression of ovarian cancer. Therefore, the BMI-1 protein may be a potential target for novel antitumor therapies $(7,43)$. Ovarian cancer is the fourth most common cause of cancer-related death in women. Ovarian tumors typically have a poor prognosis (44). In most cases, the exact cause of ovarian cancer remains unknown. Carriers of certain BRCA mutations are at significant risk. Germline mutations in the $B R C A 1$ and $B R C A 2$ genes contribute to $\sim 18 \%$ of hereditary ovarian tumors, conferring an estimated lifetime risk of $15-50 \%(45,46)$. The risk increases with age and decreases with the number of pregnancies. Treatment usually involves chemotherapy, surgery, and sometimes radiotherapy. The major limitation of standard treatment using taxane and platinum analogues (cisplatin and carboplatin) is the development of chemoresistance (47). Inhibition of apoptotic cell death is generally accepted as one of the major contributing factors to chemoresistance. Despite high initial response rates to aggressive primary therapy, most ovarian cancers develop drug resistance, resulting in patient death (48). Unfortunately, the 5-year survival rate for these patients has not exceeded $20-25 \%$. Hence, there is a critical need to develop better therapeutic agents and strategies $(49,50)$. However, it 
is unknown whether BMI-1 directly affects metastasis and progression in ovarian tumorigenesis. In this study, we provide new evidence that BMI-1 ultimately enhances tumor metastasis by increasing BMI-1-dependent PI3K/mTOR/4E-BP1 phosphorylation. First, higher BMI-1 expression activated tumor metastasis by suppressing sMEK1-stimulated apoptotic cell death via control of various cell cycle- and apoptosisassociated proteins, such as p21, cyclin D1, p53 and Bcl-2 family genes. Second, BMI-1 directly binds to sMEK1 and the bound sMEK1 inactivates BMI-1, causing overexpression of sMEK1 in ovarian tumor cells. Third, induction of the BMI-1-regulated PI3K/mTOR/4E-BP1 signaling pathway and tumor metastasis was remarkably suppressed by transient overexpression of sMEK1.

Cancer cell invasion and metastasis are regulated by many factors that can induce or enhance cell motility, demolition of the cellular matrix, angiogenesis, and various biological and physiological events at the molecular level. High BMI-1 expression is strongly associated with advanced stages of cancer and carcinomas with serous histology. BMI-1 expression displayed a significant inverse association with overall and mean patient survival. For example, Wang et al (51) demonstrated in vitro and in vivo that BMI-1 silencing synergizes with enhanced oxidative stress, leading to accumulated DNA damage and apoptotic cell death. Subsequently, knockdown of BMI-1 can effectively inhibit tumor cell proliferation and tumorigenicity in several tumors. Silencing BMI-1 by RNA interference can promote senescence and effectively decrease metastasis of gastric cancer cells (52-54). In addition, $\mathrm{Wu}$ et al (55) validated that BMI-1 functions as an oncogene in osteosarcoma and enhances tumorigenicity and resistance to chemotherapy. BMI-1 knockdown sensitized cells to cisplatininduced apoptotic cell death via suppression of the PI3K/ Akt signaling pathway. Bax, $\mathrm{Mcl}-1$ and $\mathrm{Bcl}-2$ proteins are well-known pivotal regulators of apoptotic cell death and cell growth. As indicated in Fig. 1D, Bax expression was decreased compared with non-transfectants, while Bcl-xL, Mcl-1 and Bcl-2 expression levels were increased by BMI-1. In support of these results, in cells transfected with a specific BMI-1 RNAi (siBMI-1), Bax expression was enhanced, whereas Bcl-xL, Mcl-1 and Bcl-2 were remarkably decreased by siBMI-1. PI3K communicates with 3-phosphoinositide-dependent protein kinase-1 (PDK1) and regulates cell death, cell growth, or possibly both through Akt/mTOR phosphorylation. Our data demonstrate that sMEK1 suppresses PI3K and Akt activation via BMI-1 but has no effect on PI3K inhibitors, such as wortmannin and LY294002 (Fig. 4A). These results indicate that BMI-1 promotes key signaling regulators during tumor cell progression.

In conclusion, our findings provide important new insights in cancer-related cell metastasis and tumorigenesis. Overall, we have shown that ectopic expression of sMEK1 contributes to enhanced metastatic potential via disruption of the PI3K/mTOR/4E-BP1 signaling pathways, which may be associated with BMI-1-sMEK1 interaction and transcriptional regulation of the mTOR signaling pathway. We postulate that targeting sMEK1 may provide a new strategy for modulating cancer metastasis and may serve as a novel therapeutic target for BMI-1-associated diseases, including various solid tumors.

\section{Acknowledgements}

This study was supported by a grant from the National Cancer Center, Korea (NCC-1410312-3).

\section{References}

1. Jacobs JJ, Kieboom K, Marino S, DePinho RA and van Lohuizen M: The oncogene and Polycomb-group gene bmi-1 regulates cell proliferation and senescence through the ink4a locus. Nature 397: 164-168, 1999.

2. Song LB, Zeng MS, Liao WT, Zhang L, Mo HY, Liu WL, Shao JY, Wu QL, Li MZ, Xia YF, et al: Bmi-1 is a novel molecular marker of nasopharyngeal carcinoma progression and immortalizes primary human nasopharyngeal epithelial cells. Cancer Res 66: 6225-6232, 2006.

3. Li J, Gong LY, Song LB, Jiang LL, Liu LP, Wu J, Yuan J, Cai JC, He M, Wang L, et al: Oncoprotein Bmi-1 renders apoptotic resistance to glioma cells through activation of the IKK-nuclear factor-kappaB pathway. Am J Pathol 176: 699-709, 2010.

4. Guo BH, Feng Y, Zhang R, Xu LH, Li MZ, Kung HF, Song LB and Zeng MS: Bmi-1 promotes invasion and metastasis, and its elevated expression is correlated with an advanced stage of breast cancer. Mol Cancer 10: 10, 2011.

5. Itahana K, Zou Y, Itahana Y, Martinez JL, Beausejour C, Jacobs JJ, Van Lohuizen M, Band V, Campisi J and Dimri GP: Control of the replicative life span of human fibroblasts by p16 and the polycomb protein Bmi-1. Mol Cell Biol 23: 389-401, 2003.

6. Bhattacharya R, Nicoloso M, Arvizo R, Wang E, Cortez A, Rossi S, Calin GA and Mukherjee P: MiR-15a and MiR-16 control Bmi-1 expression in ovarian cancer. Cancer Res 69: 9090-9095, 2009.

7. Honig A, Weidler C, Häusler S, Krockenberger M, Buchholz S, Köster F, Segerer SE, Dietl J and Engel JB: Overexpression of polycomb protein BMI-1 in human specimens of breast, ovarian, endometrial and cervical cancer. Anticancer Res 30: 1559-1564, 2010.

8. Tong YQ, Liu B, Zheng HY, He YJ, Gu J, Li F and Li Y: Overexpression of BMI-1 is associated with poor prognosis in cervical cancer. Asia Pac J Clin Oncol 8: e55-e62, 2012.

9. Abdouh M, Facchino S, Chatoo W, Balasingam V, Ferreira J and Bernier G: BMI1 sustains human glioblastoma multiforme stem cell renewal. J Neurosci 29: 8884-8896, 2009.

10. Kim JH, Yoon SY, Kim CN, Joo JH, Moon SK, Choe IS, Choe YK and Kim JW: The Bmi-1 oncoprotein is overexpressed in human colorectal cancer and correlates with the reduced p16INK4a/ p14ARF proteins. Cancer Lett 203: 217-224, 2004

11. Kreso A, van Galen P, Pedley NM, Lima-Fernandes E, Frelin C, Davis T, Cao L, Baiazitov R, Du W, Sydorenko N, et al: Selfrenewal as a therapeutic target in human colorectal cancer. Nat Med 20: 29-36, 2014.

12. van Kemenade FJ, Raaphorst FM, Blokzijl T, Fieret E, Hamer KM, Satijn DP, Otte AP and Meijer CJ: Coexpression of BMI-1 and EZH2 polycomb-group proteins is associated with cycling cells and degree of malignancy in B-cell non-Hodgkin lymphoma. Blood 97: 3896-3901, 2001.

13. Balasubramanian S, Lee K, Adhikary G, Gopalakrishnan R, Rorke EA and Eckert RL: The Bmi-1 polycomb group gene in skin cancer: Regulation of function by (-)-epigallocatechin3-gallate. Nutr Rev 66 (Suppl 1): S65-S68, 2008.

14. Cui H, Hu B, Li T, Ma J, Alam G, Gunning WT and Ding HF: Bmi-1 is essential for the tumorigenicity of neuroblastoma cells. Am J Pathol 170: 1370-1378, 2007.

15. Yin T, Wei H, Leng Z, Yang Z, Gou S, Wu H, Zhao G, Hu X and Wang C: Bmi-1 promotes the chemoresistance, invasion and tumorigenesis of pancreatic cancer cells. Chemotherapy 57: 488-496, 2011

16. Lindström MS, Klangby U and Wiman KG: p14ARF homozygous deletion or MDM2 overexpression in Burkitt lymphoma lines carrying wild type p53. Oncogene 20: 2171-2177, 2001.

17. Dhawan S, Tschen SI and Bhushan A: Bmi-1 regulates the Ink4a/ Arf locus to control pancreatic beta-cell proliferation. Genes Dev 23: 906-911, 2009.

18. Jiang L, Li J and Song L: Bmi-1, stem cells and cancer. Acta Biochim Biophys Sin (Shanghai) 41: 527-534, 2009.

19. Bracken AP, Dietrich N, Pasini D, Hansen KH and Helin K: Genome-wide mapping of Polycomb target genes unravels their roles in cell fate transitions. Genes Dev 20: 1123-1136, 2006. 
20. Fan C, He L, Kapoor A, Rybak AP, De Melo J, Cutz JC and Tang D: PTEN inhibits BMI1 function independently of its phosphatase activity. Mol Cancer 8: 98, 2009.

21. Kimura M, Takenobu H, Akita N, Nakazawa A, Ochiai H, Shimozato O, Fujimura Y, Koseki H, Yoshino I, Kimura H, et al: Bmil regulates cell fate via tumor suppressor WWOX repression in small-cell lung cancer cells. Cancer Sci 102: 983-990, 2011.

22. Cao L, Bombard J, Cintron K, Sheedy J, Weetall ML and Davis TW: BMI1 as a novel target for drug discovery in cancer. J Cell Biochem 112: 2729-2741, 2011.

23. Yong KJ, Basseres DS, Welner RS, Zhang WC, Yang H, Yan B, Alberich-Jorda M, Zhang J, de Figueiredo-Pontes LL, Battelli C, et al: Targeted BMI1 inhibition impairs tumor growth in lung adenocarcinomas with low CEBP $\alpha$ expression. Sci Transl Med 8: 350ra104, 2016

24. Yin T, Zhang Z, Cao B, Duan Q, Shi P, Zhao H, Camara SN, Shen $Q$ and Wang C: Bmil inhibition enhances the sensitivity of pancreatic cancer cells to gemcitabine. Oncotarget 7 : 37192-37204, 2016.

25. Banerjee Mustafi S, Chakraborty PK, Naz S, Dwivedi SK, Street M, Basak R, Yang D, Ding K, Mukherjee P and Bhattacharya R: MDR1 mediated chemoresistance: BMI1 and TIP60 in action. Biochim Biophys Acta 1859: 983-993, 2016.

26. Hastie CJ, Vázquez-Martin C, Philp A, Stark MJ and Cohen PT: The Saccharomyces cerevisiae orthologue of the human protein phosphatase 4 core regulatory subunit $\mathrm{R} 2$ confers resistance to the anticancer drug cisplatin. FEBS J 273: 3322-3334, 2006.

27. Chen GI, Tisayakorn S, Jorgensen C, D'Ambrosio LM Goudreault M and Gingras AC: PP4R4/KIAA1622 forms a novel stable cytosolic complex with phosphoprotein phosphatase 4 . J Biol Chem 283: 29273-29284, 2008.

28. Chowdhury D, Xu X, Zhong X, Ahmed F, Zhong J, Liao J Dykxhoorn DM, Weinstock DM, Pfeifer GP and Lieberman J: A PP4-phosphatase complex dephosphorylates gamma-H2AX generated during DNA replication. Mol Cell 31: 33-46, 2008

29. Nakada S, Chen GI, Gingras AC and Durocher D: PP4 is a gamma H2AX phosphatase required for recovery from the DNA damage checkpoint. EMBO Rep 9: 1019-1026, 2008.

30. Byun HJ, Kim BR, Yoo R, Park SY and Rho SB: sMEK1 enhances gemcitabine anti-cancer activity through inhibition of phosphorylation of Akt/mTOR. Apoptosis 17: 1095-1103, 2012.

31. Bertram PG, Choi JH, Carvalho J, Ai W, Zeng C, Chan TF and Zheng XF: Tripartite regulation of Gln $3 p$ by TOR, Ure $2 p$, and phosphatases. J Biol Chem 275: 35727-35733, 2000.

32. Mihindukulasuriya KA, Zhou G, Qin J and Tan TH: Protein phosphatase 4 interacts with and down-regulates insulin receptor substrate 4 following tumor necrosis factor-alpha stimulation. J Biol Chem 279: 46588-46594, 2004.

33. Gingras AC, Caballero M, Zarske M, Sanchez A, Hazbun TR, Fields S, Sonenberg N, Hafen E, Raught B and Aebersold R: A novel, evolutionarily conserved protein phosphatase complex involved in cisplatin sensitivity. Mol Cell Proteomics 4: $1725-1740,2005$

34. Zhang X, Ozawa Y, Lee H, Wen YD, Tan TH, Wadzinski BE and Seto E: Histone deacetylase 3 (HDAC3) activity is regulated by interaction with protein serine/threonine phosphatase 4 . Genes Dev 19: 827-839, 2005.

35. Yoon YS, Lee MW, Ryu D, Kim JH, Ma H, Seo WY, Kim YN, Kim SS, Lee CH, Hunter T, et al: Suppressor of MEK null (SMEK)/protein phosphatase 4 catalytic subunit (PP4C) is a key regulator of hepatic gluconeogenesis. Proc Natl Acad Sci USA 107: 17704-17709, 2010.

36. Dong SM, Byun HJ, Kim BR, Lee SH, Trink B and Rho SB: Tumor suppressor BLU enhances pro-apoptotic activity of sMEK1 through physical interaction. Cell Signal 24: 1208-1214, 2012.

37. Kim BR, Seo SH, Park MS, Lee SH, Kwon Y and Rho SB: sMEK1 inhibits endothelial cell proliferation by attenuating VEGFR-2-dependent-Akt/eNOS/HIF-1 $\alpha$ signaling pathways. Oncotarget 6: 31830-31843, 2015.
38. Rho SB, Song YJ, Lim MC, Lee SH, Kim BR and Park SY: Programmed cell death 6 (PDCD6) inhibits angiogenesis through $\mathrm{PI} 3 \mathrm{~K} / \mathrm{mTOR} / \mathrm{p} 70 \mathrm{~S} 6 \mathrm{~K}$ pathway by interacting of VEGFR-2. Cell Signal 24: 131-139, 2012.

39. Glinsky GV: Stem cell origin of death-from-cancer phenotypes of human prostate and breast cancers. Stem Cell Rev 3: 79-93, 2007.

40. Vrzalikova K, Skarda J, Ehrmann J, Murray PG, Fridman E, Kopolovic J, Knizetova P, Hajduch M, Klein J, Kolek V, et al: Prognostic value of Bmi-1 oncoprotein expression in NSCLC patients: A tissue microarray study. J Cancer Res Clin Oncol 134: 1037-1042, 2008

41. Wang H, Pan K, Zhang HK, Weng DS, Zhou J, Li JJ, Huang W, Song HF, Chen MS and Xia JC: Increased polycomb-group oncogene Bmi-1 expression correlates with poor prognosis in hepatocellular carcinoma. J Cancer Res Clin Oncol 134: 535-541, 2008.

42. Li DW, Tang HM, Fan JW, Yan DW, Zhou CZ, Li SX, Wang XL and Peng ZH: Expression level of Bmi-1 oncoprotein is associated with progression and prognosis in colon cancer. J Cancer Res Clin Oncol 136: 997-1006, 2010.

43. Gavrilescu MM, Todosi AM, Aniţei MG, Filip B and Scripcariu V: Expression of bmi-1 protein in cervical, breast and ovarian cancer. Rev Med Chir Soc Med Nat Iasi 116: 1112-1117, 2012.

44. Chobanian N and Dietrich CS III: Ovarian cancer. Surg Clin North Am 88: 285-299, vi, 2008.

45. Lakhani SR, Manek S, Penault-Llorca F, Flanagan A, Arnout L, Merrett S, McGuffog L, Steele D, Devilee P, Klijn JG, et al: Pathology of ovarian cancers in BRCA1 and BRCA 2 carriers. Clin Cancer Res 10: 2473-2481, 2004.

46. Stavropoulou AV, Fostira F, Pertesi M, Tsitlaidou M, Voutsinas GE, Triantafyllidou O, Bamias A, Dimopoulos MA, Timotheadou E, Pectasides D, et al: Prevalence of BRCA1 mutations in familial and sporadic Greek ovarian cancer cases. PLoS One 8: e58182, 2013.

47. Shih KK and Chi DS: Maximal cytoreductive effort in epithelial ovarian cancer surgery. J Gynecol Oncol 21: 75-80, 2010.

48. Agarwal R and Kaye SB: Ovarian cancer: Strategies for overcoming resistance to chemotherapy. Nat Rev Cancer 3: 502-516, 2003.

49. Ozols RF: Treatment goals in ovarian cancer. Int J Gynecol Cancer 15 (Suppl 1): 3-11, 2005.

50. Spannuth WA, Nick AM, Jennings NB, Armaiz-Pena GN, Mangala LS, Danes CG, Lin YG, Merritt WM, Thaker PH, Kamat AA, et al: Functional significance of VEGFR-2 on ovarian cancer cells. Int J Cancer 124: 1045-1053, 2009.

51. Wang E, Bhattacharyya S, Szabolcs A, Rodriguez-Aguayo C, Jennings NB, Lopez-Berestein G, Mukherjee P, Sood AK and Bhattacharya R: Enhancing chemotherapy response with Bmi-1 silencing in ovarian cancer. PLoS One 6: e17918, 2011.

52. Xin T, Zhang FB, Sui GJ and Jin XM: Bmi-1 siRNA inhibited ovarian cancer cell line growth and decreased telomerase activity. Br J Biomed Sci 69: 62-66, 2012.

53. Gao FL, Li WS, Liu CL and Zhao GQ: Silencing Bmi-1 enhances the senescence and decreases the metastasis of human gastric cancer cells. World J Gastroenterol 19: 8764-8769, 2013.

54. Zhang Y, Zhang YL, Chen HM, Pu HW, Ma WJ, Li XM, Ma H and Chen X: Expression of Bmi-1 and PAI-1 in esophageal squamous cell carcinoma. World J Gastroenterol 20: 5533-5539, 2014.

55. Wu Z, Min L, Chen D, Hao D, Duan Y, Qiu G and Wang Y: Overexpression of BMI-1 promotes cell growth and resistance to cisplatin treatment in osteosarcoma. PLoS One 6: e14648, 2011. 